\title{
$(12.00 .08)$
}

Тищенко Ю.Ю.

\section{К BOIPOCY О ВОзMOXнОсти \\ ВЫДЕЛЕНИЯ И ИСПОЛЬЗОВАНИЯ ПОНЯТИЯ «КРИМИНОЛОТИЧЕСКАЯ ОБСТАНОВКА»}

Tishchenko Yu.Yu.

\section{TO THE QUESTION ABOUT THE POSSIBILITY OF ISOLATING AND USING THE CONCEPT OF "CRIMINOLOGICAL SITUATION"}

При исследовании проблем борьбы с преступностью автор приходит к выводу, что на сегодняшний день имеется необходимость описания не только происходящих изменений преступности, при наличии сведений о ее характеристиках, а последовательное исследование сути происходящих противоправных явлений. В статье автор рассматривает, прежде всего, определение роли новейших тенденций преступности и установлению изменений при совершении преступлений в прошлом, полагает, что получение подобной информации может послужить основой для выработки достаточно обоснованной и аргументированной позиции, позволяющей сформировать стратегию деятельности правоохранительных органов по противодействию преступности и обеспечить подготовку новой программы борьбы с ней.

Ключевые слова: преступность, профилактика, криминологическая обстановка, оперативная обстановка, противодействие преступности, состояние преступности, детерминанты преступности.

When studying the problems of combating crime, the author comes to the conclusion that today there is a need to describe not only the changes in crime that are taking place, if there is information about its characteristics, but a consistent study of the essence of the illegal phenomena that are taking place. In the article, the author considers, first of all, the definition of the role of the latest crime trends and the establishment of changes in the commission of crimes in the past, believes that obtaining such information can serve as a basis for developing a sufficiently substantiated and reasoned position that allows forming a strategy for law enforcement agencies to combat crime and ensure the preparation of a new program to combat it.

Keywords: crime, prevention, criminological situation, operational situation, crime prevention, state of crime, determinants of crime.

В настоящее время в числе некоторых важнейших проблем, вызывающих общественную тревогу находится состояние преступности. Достаточно неблагоприятная динамика развития преступности, рост ее степени общественной опасности, высокий уровень увеличения ее профессионального мастерства и организованности все более часто стоят на пути социального прогресса нашего общества, становятся препятствием для нормального осуществления политических и экономических преобразований. На современном этапе необходимо признать, что нынешняя преступность прилагает все усилия, направленные на изменение своего качественного, количественного и сущностного порядка. Полагаем, что на сегодняшний день имеется необходимость описания не только происходящих изменений преступности, при наличии сведений о ее характеристиках, а последовательное исследование сути происходящих противоправных явлений. В дан- 
ной работе представляется необходимым прибегнуть, прежде всего, к определению роли новейших тенденций преступности и установлению изменений при совершении преступлений в прошлом. Считаем, что получение подобной информации может послужить основой для выработки достаточно обоснованной и аргументированной позиции, позволяющей сформировать стратегию деятельности правоохранительных органов по противодействию преступности и обеспечить подготовку новой программы борьбы с ней.

В данной статье предполагается рассмотреть в основном с методологических позиций недостаточно освещенный, по нашему мнению, в криминологической литературе вопрос, касающийся самого понятия и сущности криминологической обстановки и ее влияния на познание проявлений преступности.

В современный период, когда объемы информации резко возросли во всех сферах деятельности, имеет место беспорядочное использование терминов, определений, которые уже не отражают во всей полноте сущности обозначаемых процессов и явлений. Перевод терминологии одной научной сферы в терминологический аппарат другой для обозначения одного и того же процесса нередко приводит к тому, что данный термин теряет свой сущностный смысл применительно к правоохранительной сфере, в которой он используется [1, с. 9-10]. Это приводит к множеству вариантов толкования и делает невозможным однозначное понимание. В частности, вызывает научный, а также и прикладной интерес сущностный анализ понятий «криминологическая» и «оперативная обстановка».

В обыденном понимании оперативная обстановка характеризует какие-либо быстроменяющиеся обстоятельства, факторы, условия, которые требуют принятия неотложных тактических решений в условиях дефицита времени. Оперативность предполагает скорость, действенность, эффективность, своего рода быстроту, стремительность, решительность, незамедлительность предпринимаемых мер [1, с. 9-10].

Отсюда и исходит термин «оперативная обстановка», который используется в различных областях жизнедеятельности. Считаем необходимым отметить, что в настоящее время, такое достаточно широко применяемое понятие, как оперативная обстановка и сложившаяся система ее анализа на основе наблюдения за ней все чаще в полной мере перестают удовлетворять потребности практики правоохранительных органов и не привносят новых методов, направленных на повышение эффективности, необходимых для качественной организации противодействия преступности в целом. Совершение новых противоправных деяний приводит к возникновению сложных криминологических понятий. К одному из них можно отнести понятие криминологической обстановки, включающей в себя как наблюдение за динамикой ее развития, так и изучение факторов ее детерминирующих.

В условиях обобщения позиций авторов, ранее исследовавших такое понятие, как оперативная обстановка, можно установить, что большинство ученых (Богданов Б.Е., Горяинов К.К., Гребельский Л.В., Лукашов В.А., Самойлов В.Г., Синилов Г.К.) определяли ее как в целом совокупность реальных условий для решения правоохранительными органами конкретных задач, направленных на противодействие преступности.

Отметим, что в структуру оперативной обстановки практически все вышеназванные ученые включали следующие ее составляющие: состояние преступности; состояние среды; наличие сил и средств и эффективность их использования. Однако круг задач, решаемых на основе изучения оперативной обстановки оказался значительно шире по своим масштабам, целям, задачам. В частности, в него входила и организация оперативного обслуживания объектов и территории, охрана общественного порядка и общественной безопасности, методика раскрытия и расследования преступлений, тактические особенности предупреждения и пресечения преступлений, а также задержание виновных лиц в совершении противоправных деяний.

В настоящее время вопрос предупреждения преступности приобретает политическую окраску. Социальная природа преступности и ее причин соответственно определяет и социальный характер мер ее предупреждения. Поддерживаем мнение А.В. Абрамова о том, что укрепление правопорядка не может рассматриваться субъектом управления только как ведомственная проблема, так как его состояние определяется множеством объективных факторов, лежащих вне сферы воздействия органов внутренних дел [2, с. 445].

Одним из наиболее интересных на наш взгляд определений, касающихся деятельности по определению сущности оперативной обстановки является констатация того, что изучение оперативной 
обстановки представляет собой ежедневный и постоянный анализ поступающей информации, являющейся общей частью аналитической работы руководства и отдельных сотрудников правоохранительных органов. В основе данной работы лежит поэтапное изучение сведений о выявлении тенденций в уровне, структуре и динамике противоправных деяний. Далее происходит установление факторов, влияющих на возникновение указанных тенденций с целью принятия немедленных мер к устранению причин, порождающих негативные явления, либо оценка их возможного влияния на динамику преступности и использование полученных выводов и результатов для прогнозирования ее состояния [3, с. 40].

По нашему мнению, выдвинутое ранее определение, безусловно, заслуживает внимания и имело свою актуальность в указанный период времени. Однако мы полагаем, что в нынешнее время вряд ли имеется возможность и необходимость ежедневного сбора и переработки сведений, представляющих собой огромный массив информации для решения столь глобальных задач. Представляется, что оценка обстановки, ее условий и причин возникновения требуется постоянно для принятия необходимых мер реагирования, однако правоохранительным органам приходится параллельно решать и тактические вопросы предупреждения, пресечения и раскрытия преступлений, охраны общественного порядка и общественной безопасности, исполнения наказаний.

Таким образом, приходится констатировать, что если речь идет о всестороннем изучении и оценке уровня преступности в целом, определении ее тенденций, постоянно возникающих изменений, о выявлении факторов, оказывающих влияние на сложившиеся ситуации, о выработке стратегии или концепции, системы профилактических мер, рассчитанных на определенный или продолжительный период времени, то полагаем, что приведенный подход просто неприемлем в настоящее время.

Представляется, достаточно интересным мнение Г.А. Майстренко, который отмечает, что на современном этапе для правильной организации работы по сбору, систематизации и оценки информации о складывающейся оперативной обстановке в первую очередь представляется необходимым: определить перечень нужной информации, источники ее получения; выработать формы ее накопления и систематизации, перечень подготавли- ваемых аналитических документов и установить периодичность их представления; назначить лиц, ответственных за анализ основных направлений деятельности служб [4, с. 3].

Однако необходимо учитывать, что само определение оперативная обстановка является достаточно ведомственным понятием, наиболее относящимся к сфере деятельности правоохранительных органов, занимающихся противодействием совершению противоправных деяний. По нашему мнению, рассматриваемое понятие должно больше использоваться в процессе осуществления анализа организации и управления деятельностью правоохранительных органов с целью выработки комплекса действенных мер для оперативного реагирования на возникающие явления противоправного характера в условиях, когда достаточно быстро происходит изменение обстановки.

Необходимо отметить, что факторы, детерминирующие преступность подвержены в определенной степени медленным изменениям, а время для анализа динамики и прогнозирования состояния преступности, а также для выработки мер борьбы с ней и внесения необходимых изменений и дополнений в законодательные акты и систему функционирования правоохранительных органов представляет собой долгосрочную перспективу, именно поэтому мы полагаем, что данная деятельность выходит за пределы оперативного реагирования и не может рассматриваться в качестве оперативной обстановки, как это ранее понималось.

Учитывая приведенные выше доводы по рассматриваемой тематике, представляется необходимым ввести в научную среду такое определение, которое бы соответствовало признакам изучаемого понятия и могло применяться самостоятельно правоохранительными органами в целях изучения именно состояния преступности. Поэтому нами предлагается наряду с понятием оперативная обстановка выделить такое понятие как «криминологическая обстановка», которая бы включала в себя изучение состояния преступности как результат действия детерминирующих факторов, имеющих различную природу возникновения и действующих на определенной территории в настоящее время. То есть данная обстановка будет выступать как совокупность свойств и отношений преступности и воздействующих на нее факторов и тем самым отображать сущность определенного круга общественных отношений и происходящих процессов в их развитии. 
Отметим, что понятия «криминологическая и оперативная обстановка» тесно взаимосвязаны между собой, однако полагаем, что они могут применяться самостоятельно. Их соотношение, выявление сходств и различий имеет не только теоретическое, но и практическое значение. Изучение и анализ оперативной обстановки относится больше к тактическим особенностям противодействия противоправным деяниям, чаще используемым при планировании и осуществлении конкретных мероприятий с учетом оценки происходящих негативных явлений, которые являются значимыми для организации и повышения эффективности деятельности правоохранительных органов. В данном случае происходит совмещение в оценке состояния преступности, характеристики сил и средств с условиями деятельности правоохранительных органов, поскольку в процессе организации и проведения конкретных мероприятий, направленных на противодействие преступности важно иметь представление, как о ее состоянии, так и обстоятельствах, которые могут повлиять на эффективность проводимых мероприятий.

Вышеуказанные условия могут иметь значение также и для оценки криминологической обстановки, но они не будут выступать в качестве основных условий, определяющих ее состояние, поскольку в ней, прежде всего, необходимо установить уровень состояния преступности и его социальную обусловленность. То есть, при оценке криминологической обстановки необходимо проанализировать состояние преступности и детерминирующие ее факторы с позиции отношения общества к этому явлению в условиях социальной действительности. Тогда как оценка оперативной обстановки состоит в определении реальных условий в рамках выполнения задач и функций правоохранительных органов.

На наш взгляд, одно из ранее высказанных мнений по данному поводу заслуживает внимания. В частности, А.Б. Сахаров утверждал, что деятельность органов внутренних дел является лишь частным аспектом борьбы общества с преступными проявлениями, она выступает одним из позитивных факторов, условием влияния на состояние преступности, однако определение степени такого влияния невозможно без учета совокупного воздей- ствия криминологических факторов [5, с. 11]. Полагаем, что данное мнение лишь свидетельствует о том, что разграничение понятий «криминологическая и оперативная обстановка» является одним из существенных условий объективной оценки эффективной деятельности органов внутренних дел и возможно всей системы правоохранительных органов.

Полагаем, что криминологическая обстановка при изучении ее любыми субъектами может выступать как часть социальной действительности, как объективное социально-правовое явление, которое должно иметь общую оценку для всех субъектов правоохранительной деятельности, независимо от их ведомственных подходов и интересов, поскольку общесоциальная оценка необходима для решения стратегических задач нашего общества и государства в системе противодействия преступности.

Отметим, что конечно для каждого из субъектов правоохранительных органов необходима своя оценка, соотносимая с имеющимися силами и средствами, реальными возможностями воздействия с учетом конкретных условий. Для конкретных правоохранительных органов оценка криминологической обстановки должна выступать в качестве основы для анализа происходящих криминологических процессов и значимых явлений с учетом специфики их деятельности, их возможностей и особенностей воздействия на эти процессы [6, с. 15].

Таким образом, представляется, что на сегодняшний день нам необходима именно выработанная стратегия, основанная на оценке криминологической обстановки, которая может определить тактические задачи каждого субъекта правоохранительных органов. При этом эффективность решения данных задач, принимаемые решения, характер действий во многом будут зависеть от конкретных условий и складывающихся ситуаций на определенной территории, в определенное время. Но все эти условия уже будут входить в содержание оперативной обстановки, которая становится производным явлением, зависящим от криминологической обстановки, поскольку она дает основополагающее представление о преступности и выступает по отношению к оперативной обстановке явлением более высокого социального уровня.

\section{Литература}

1. Ульянов А. Д., Захватов И. Ю., Болдырев У. К. Оперативная обстановка, понятие, анализ прогноз. Учебное пособие. - М.: Академия управления МВД России. 2020. - 104 c. 
2. Абрамов А.В. О соотношении понятий «оперативная обстановка» и «криминогенная обстановка». Актуальные проблемы российского права. 2009. № 3 . C. 445 .

3. Самойлов В.Г. Некоторые проблемы изучения и оценки оперативной обстановки // Информационное сообщение лаборатории проблем оперативно-розыскной работы. М., 1972. № 2. С. 40.

4. Майстренко Г.А. К вопросу о понятии «оперативная обстановка» (на примере учреждений уголовно-исполнительной системы // Административное право и практика администрирования. 2021. № 1. С. 3.

5. Сахаров А.Б. Правоохранительная деятельность и преступность // Советское государство и право. 1986. № 1. С. 11.

6. Горяинов К.К, Силаев А.И. Криминологическая обстановка и ее региональные особенности. М., 1985. С. 15.

\section{References}

1. UI'yanov A. D., Zakhvatov I. YU., Boldyrev U. K. Operativnaya obstanovka, ponyatiye, analiz prognoz. Uchebnoye posobiye. - M.: Akademiya upravleniya MVD Rossii. 2020. - $104 \mathrm{~s}$.

2. Abramov A.V. O sootnoshenii ponyatiy «operativnaya obstanovka» i «kriminogennaya obstanovka». Aktual'nyye problemy rossiyskogo prava. 2009. № 3. S. 445.

3. Samoylov V.G. Nekotoryye problemy izucheniya i otsenki operativnoy obstanovki // Informatsionnoye soobshcheniye laboratorii problem operativno-rozysknoy raboty. M., 1972. № 2. S. 40.

4. Maystrenko G.A. K voprosu o ponyatii «operativnaya obstanovka» (na primere uchrezhdeniy ugolovno-ispolnitel'noy sistemy // Administrativnoye pravo i praktika administrirovaniya. 2021. № 1. S. 3.

5. Sakharov A.B. Pravookhranitel'naya deyatel'nost' i prestupnost' // Sovetskoye gosudarstvo i pravo. 1986. № 1. S. 11.

6. Goryainov K.K, Silayev A.I. Kriminologicheskaya obstanovka i yeye regional'nyye osobennosti. M., 1985. S. 15.

ТИЩЕНКО Юрий Юрьевич, старший научный сотрудник ФКУ НИИ ФСИН России, кандидат юридических наук. 125130, г. Москва, ул. Нарвская, 15A, стр. 1. E-mail: yutish@list.ru

TISHCHENKO Yuri Yurievich, senior researcher at the Federal State Institution of Scientific Research Institute of the Federal Penitentiary Service of Russia, candidate of legal sciences. 125130, Moscow, st. Narvskaya, 15A, building 1. E-mail: yutish@list.ru 